\title{
Specimen number based diagnostic yields of suspicious axillary lymph nodes in core biopsy in breast cancer: clinical implications from a prospective exploratory study
}

\author{
Yue $\mathrm{Hu}^{1,2 \#}$, Jingsi Mei ${ }^{1,2 \#}$, Yaping Yang ${ }^{1,2 \#}$, Ran $\mathrm{Gu}^{1,2}$, Jiajie Zhong ${ }^{3}$, Xiaofang Jiang ${ }^{1,2}$, Fengtao Liu ${ }^{1,2}$, \\ Juanjuan Yong ${ }^{3}$, Hongli Wang ${ }^{1,2}$, Shiyu Shen ${ }^{1,2}$, Jing Liang ${ }^{1,2}$, Qiang Liu ${ }^{1,2}$, Chang Gong ${ }^{1,2,4}$ \\ ${ }^{1}$ Guangdong Provincial Key Laboratory of Malignant Tumor Epigenetics and Gene Regulation, ${ }^{2}$ Breast Tumor Center, ${ }^{3}$ Department of Pathology, \\ Sun Yat-sen Memorial Hospital, Sun Yat-sen University, Guangzhou, China; ${ }^{4}$ Bioland Laboratory (Guangzhou Regenerative Medicine and Health \\ Guangdong Laboratory), Guangzhou, China
}

\#These authors contributed equally to this work.

Correspondence to: Chang Gong, MD, PhD. Department of Breast Surgery, Breast Tumor Center, Sun Yat-sen Memorial Hospital, Sun Yat-sen University, 107 Yanjiang West Road, Guangzhou 510260, China. Email: gchang@mail.sysu.edu.cn; changgong282@163.com.

Background: Ultrasound (US)-guided core needle biopsy (CNB) is widely applied in the pathological diagnosis of suspicious axillary lymph nodes (ALNs) in breast cancer. However, the number of specimens removed during biopsy is currently based on the preference of the individual radiologist. This study aims to analyze the specimen number based diagnostic yields of US guided CNB of suspicious ALNs in breast cancer.

Methods: Core biopsy specimens of suspicious lymph nodes were prospectively obtained from breast cancer patients treated at our hospital between November, 2018, and July, 2019. Four specimens were obtained from each patient and labeled 1-4 in the order they were removed. Each specimen underwent pathological evaluation to determine whether metastasis had occurred. The diagnostic yields of the specimens were calculated and differences in diagnostic accuracy according to the number of specimens were evaluated by McNemar's test.

Results: A total of 167 patients were enrolled, and 139 (83.2\%) cases were identified as metastasis by CNB. The diagnostic yields were: $74.2 \%$ (specimen 1), 87.8\% (specimens 1-2), 91.2\% (specimens 1-3), and 94.6\% (specimens 1-4). The increases in diagnostic yield from specimen 1 to 1-2 and from specimens 1-2 to 1-4 were significant; however, no significant differences were detected between specimens 1-3 and the first two, or between specimens $1-4$ and the first three in this sample size. The lower diagnostic abilities for the first two specimens were associated with shorter long- and short-axis lengths of lymph nodes on US.

Conclusions: Although the second specimen contributed significant diagnostic yield of suspicious axillary lymph nodes in core biopsy in breast cancer, a minimum number cannot be determined by this study. Additional specimens may improve diagnostic yield particularly in patients with small nodes.

Keywords: Breast cancer; axillary lymph node (ALN); ultrasound (US); core needle biopsy (CNB); specimen

Submitted Aug 11, 2020. Accepted for publication Nov 20, 2020.

doi: $10.21037 /$ qims-20-1030

View this article at: http://dx.doi.org/10.21037/qims-20-1030 


\section{Introduction}

Preoperative evaluation of axillary lymph node (ALN) status in patients with non-metastatic breast cancer is crucial in informing clinical decisions on the appropriate type of axillary surgery $(1,2)$. Patients with no clinical evidence of metastatic ALNs upon initial diagnosis are first recommended to undergo sentinel lymph node biopsy (SLNB), while patients with positive ALNs who have not received neoadjuvant therapy before surgery generally undergo ALN dissection $(3,4)$. In general, if ALN metastasis is suspected, specimens should be obtained for pathological diagnosis before surgery, using imaging modalities such as ultrasound (US)-guided core needle biopsy (CNB) or fine needle aspiration (FNA), to determine whether the cancer has metastasized (5-7). US-guided CNB has been demonstrated to have higher sensitivity than FNA and is less operator dependent $(8,9)$. Previous studies have reported the sensitivity of CNB to range from $83.4 \%$ to $94 \%$ for the diagnosis of metastatic ALNs (8-11). However, the number of core specimens taken during CNB currently depends on the preference of the individual radiologist and has been reported to range from one to six $(8,10,12)$. Obtaining a sufficient but not excessive number of specimens can ensure a good diagnostic performance while shortening the procedure time and minimizing the risk of complications. However, due to a lack of clinical evidence, no consensus on the ideal number of US-guided CNB specimens required to make an adequate pathological diagnosis of ALN status with minimal puncture currently exists. This prospective study therefore aimed to analyze the diagnostic ability of different numbers of US-guided CNB specimens of suspicious ALNs in patients with newly diagnosed breast cancer.

\section{Methods}

\section{Patients}

All female patients with newly diagnosed non-metastatic breast cancer with ipsilateral abnormal ALN imaging on US between November, 2018, and July, 2019 in Sun Yatsen Memorial Hospital, were invited to participate in our study. Chest X-ray, abdominal US examination and blood tumor markers test were performed to exclude breast cancer metastases to other organs, further CT/MRI scan would be performed if suspicious finding presents. The inclusion criteria were as follows: (I) female older than 18 years; (II) patients with primary breast cancer; (III) suspicious ALN on US; (IV) received a successful CNB of the suspicious ALN. The exclusion criteria were as follows: (I) patients who could not provide informed consent or for whom CNB was considered unsafe; (II) previous ipsilateral axillary surgery; (III) no metastasis on CNB and no further axillary surgery in our hospital; (IV) CNB based on a false-positive axillary US assessment. Trial Registration: Chinese Clinical Trial Registry (ChiCTR) (http://www.chictr.org.cn), ChiCTR1800020204.

The study was conducted in accordance with the Declaration of Helsinki (as revised in 2013). This prospective study was approved by the institutional ethics committee of Sun Yat-sen Memorial Hospital (No. 2018-44). All study participants gave written informed consent, and the data were de-identified.

\section{US and biopsy}

Preoperative axillary US was performed at the same time as breast US, in line with routine practice in our center. All axillary US examinations and biopsies were performed by one of three dedicated breast radiologists (Y.H., R.G., and F.T.L.), who each have 5-10 years' experience in breast radiology and interventions.

Each examination was performed using a high-resolution US unit (S2000/S1000/Oxana 2; Siemens, Erlangen, Germany; or HS70A; Samsung, Hongcheon-gun, South Korea) with a high-frequency linear transducer. Real-time US was performed and interpreted by the same radiologist, according to usual practice in our center (13). Real-time scanning can help true cortical thickening of a lymph node to be distinguished (14) and has been used in previous studies $(15,16)$. During scanning, special attention was given to the axillary tail area $(17,18)$.

Suspicious ALNs were identified on US according to the following criteria, based on published studies: cortical thickening $(>3 \mathrm{~mm})$ or an eccentric cortex; compression or displacement of the fatty hilum; a round or irregular shape; no circumscribed margin; and non-hilar blood flow to the cortex (14,17-20). The differences in US features between suspicious and contralateral ALNs were also an important reference (14). Lymph nodes that did not meet any of these criteria were assessed as negative. The original report documented the detailed features and representative images were obtained.

Patients with abnormal lymph nodes subsequently underwent $\mathrm{CNB}$, patients without abnormal nodes directly underwent SLNB. If more than one abnormal node was 
present, the most suspicious node was selected for $\mathrm{CNB}$ at the discretion of the radiologist performing the procedure. A core biopsy instrument with a 22-mm throw (Bard MaxCore; Bard Biopsy Systems, AZ, USA) was used to obtain a 14-gauge CNB from the target ALN. The peripheral cortex was targeted specifically, and color Doppler US was used to avoid any large vessels (17). For each lymph node, 4 core specimens (labeled specimens 1-4 in the order of removal) longer than $5 \mathrm{~mm}$ and including solid tissue containing no macroscopic fat were removed from different angles, which is the usual practice in our center. All US images of CNBnegative cases were reviewed retrospectively in a nonblinded fashion by all three dedicated breast radiologists to determine if the original axillary US assessment might have been falsely positive.

\section{Histopathological evaluation}

The four CNB specimens from the same lymph node were stained immediately with tissue marking dye in four different colors (red, blue, green and black, respectively; Davidson Marking System; Bradley Products, MN, USA) and then placed into $10 \%$ neutral formalin. The specimens were stained with the different colored dyes at random, and the pathological diagnosis was not affected by the color of the dye (21). After fixation, the specimens were processed, as closely as possible and without overlap, into a single paraffin block, according to standard protocols (22). Uniform pressure was put on the specimens with a tamper so that all four were embedded in the paraffin at the same depth. One microtome section level (encompassing all four cores) was then subjected to standard histopathological examination using hematoxylin-eosin (HE) staining $(22,23)$. If suspicious cells of uncertain nature were identified, immunohistochemical staining was carried out using the broad-spectrum cytokeratin antibody AE1/3 (FLEX Monoclonal Mouse Anti-Human Cytokeratin, Clone AE1/ AE3, Ready-to-Use, Dako, CA, USA). The pathologists were blinded to the order of the colors. The four core specimens for each case were evaluated for the presence of metastasis by two pathologists (J.J.Z. and J.J.Y.), who made their diagnoses independently. A positive pathological diagnosis was considered when macro-metastasis or micrometastasis was present in the ALN, while the presence of isolated tumor cells represented a negative result. Patients with negative CNB results subsequently underwent SLNB to confirm the ALN status (Figure 1).

\section{Statistical analysis}

The primary outcome was diagnostic yield based on the number of CNB specimens (specimen number-specific yield). The secondary outcome was the correlation between the diagnostic ability of the first two specimens and clinical and US characteristics. Specimen number-specific sensitivity (diagnostic yield), specificity, accuracy, and positive and negative predictive values were calculated for CNB. Cases were finally defined as positive if metastasis was found in the lymph nodes (either by CNB or subsequent surgical biopsy). True-positivity of combined CNB specimens was defined as any of the combined cores presenting a positive diagnosis.

All statistical analyses were performed using SPSS, version 19 (IBM, Chicago, IL, USA). McNemar's test was used to evaluate significant differences between the specimen number-specific yields of CNB with respect to the final result. Continuous and categorical variables were evaluated by independent samples $t$-test and $\chi^{2}$ test, respectively. $\mathrm{P}<0.05$ was considered to indicate a significant difference.

\section{Results}

\section{Patient characteristics}

Between November, 2018, and July, 2019, 192 female patients with newly diagnosed breast cancer and ipsilateral abnormal ALN imaging on US were initially recruited. Twenty-five patients were excluded due to undergoing ipsilateral axillary surgery $(\mathrm{n}=15)$, having no available data on pathological diagnosis for each CNB specimen $(\mathrm{n}=4)$, having a negative CNB result but no subsequent open surgery performed in our hospital $(n=4)$, or having a negative $\mathrm{CNB}$ result based on a false-positive US assessment pre-CNB $(\mathrm{n}=2)$. Finally, 167 patients (mean age: 50.2 10.4 years, range, 26-88 years) with $167 \mathrm{CNBs}$ were included in the analysis (Figure 2). Table 1 shows the patients' demographic information and characteristics. No severe CNB-related complications were observed. Four patients experienced transient sharp pain, which was controlled by extra local anesthesia. Two patients experienced bleeding, which was stopped by direct compression.

Of the 167 eligible and evaluable patients, 139 (83.2\%) were identified as positive for lymph node metastasis by CNB. Among these patients, 109 cases were diagnosed as metastasis based on the first specimen, 129 cases based on the first two specimens, 134 and 139 cases based on 


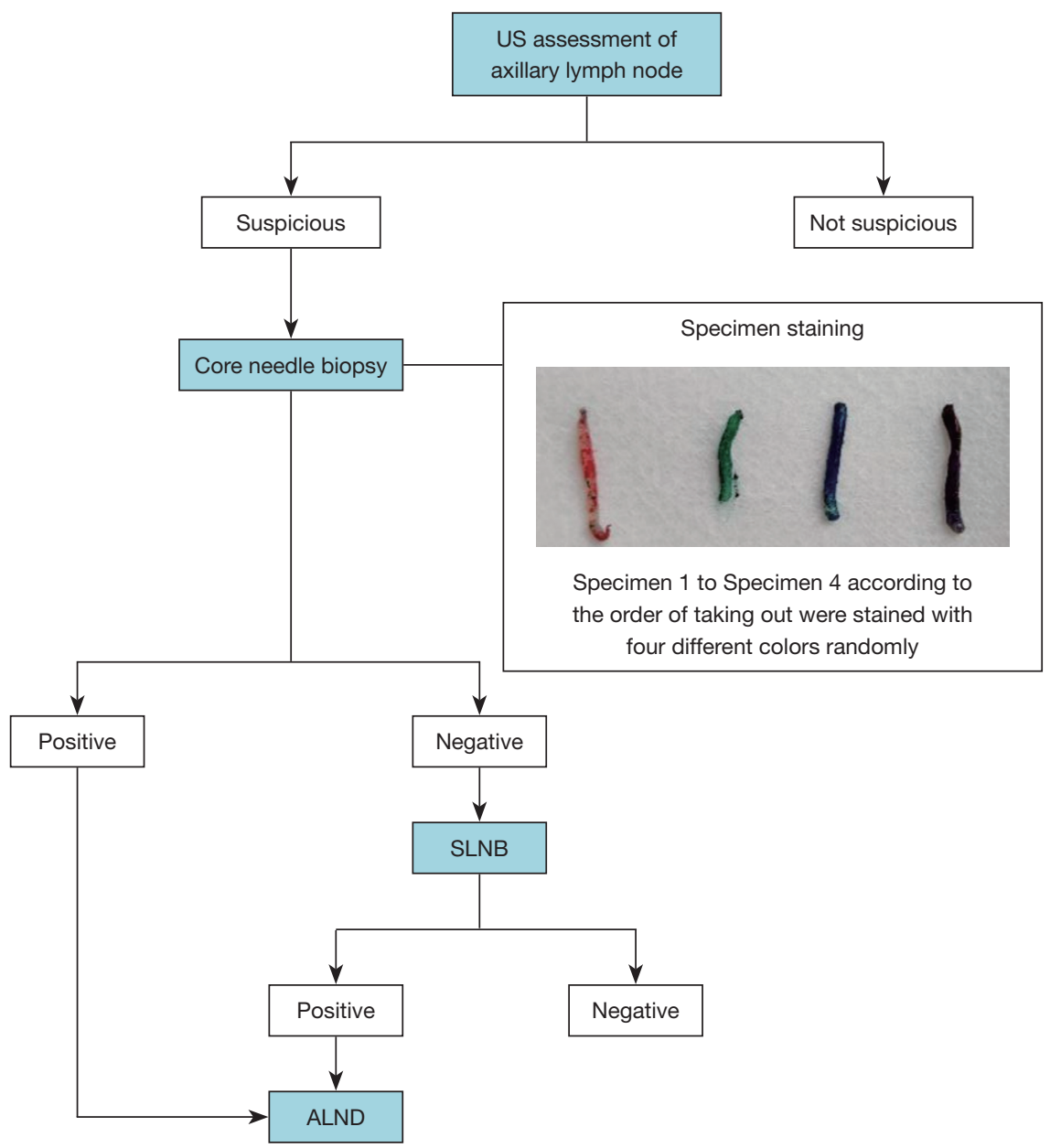

Figure 1 Algorithm for axillary staging. US, ultrasound; SLNB, sentinel lymph node biopsy; ALND, axillary lymph node dissection.

the first three and all four specimens, respectively. Of the 139 patients, 124 underwent open surgery and 79 received preoperative neoadjuvant chemotherapy (NAC).

Of the $28(16.8 \%)$ patients with a CNB-negative diagnosis, 17 were assigned directly to open surgery, 6 of whom were identified with positive lymph nodes. The remaining 11 of the 28 patients underwent NAC followed by open surgery, and 2 patients were finally identified with positive lymph nodes (Figure 2).

\section{Specimen number-specific diagnostic performance}

The diagnostic performance according to the number of specimens is shown in Table 2. Metastasis was detected in 438 (74.5\%) of the $588 \mathrm{CNB}$ specimens obtained from the 147 patients who were ultimately found to have positive
ALNs. The sensitivity of specimens $1,2,3$, and 4 was $74.2 \%$ (109/147), $76.2 \%$ (112/147), 71.4\% (105/147), and $76.2 \%$ (112/147), respectively. No significant differences were detected between the four specimens in terms of sensitivity (all $\mathrm{P}>0.05$ ). The sensitivity of the first two specimens [1-2] was significantly higher than that of the first specimen $(87.8 \%$ vs. $74.2 \%, \mathrm{P}<0.001)$. Albeit no significant differences were detected between the sensitivity of the first three specimens [1-3] versus the first two [1-2], or between all four specimens [1-4] versus the first three [1-3] (91.2\% vs. $87.8 \%$ and $94.6 \%$ vs. $91.2 \%$, respectively, both $\mathrm{P}=0.06$ ). The sensitivity of all four specimens [1-4] was significantly higher than that of the first two [1-2] (94.6\% vs. $87.8 \%, \mathrm{P}=0.002)$. The specificity was $100 \%$ for all specimens, with no CNB false-positive cases. 


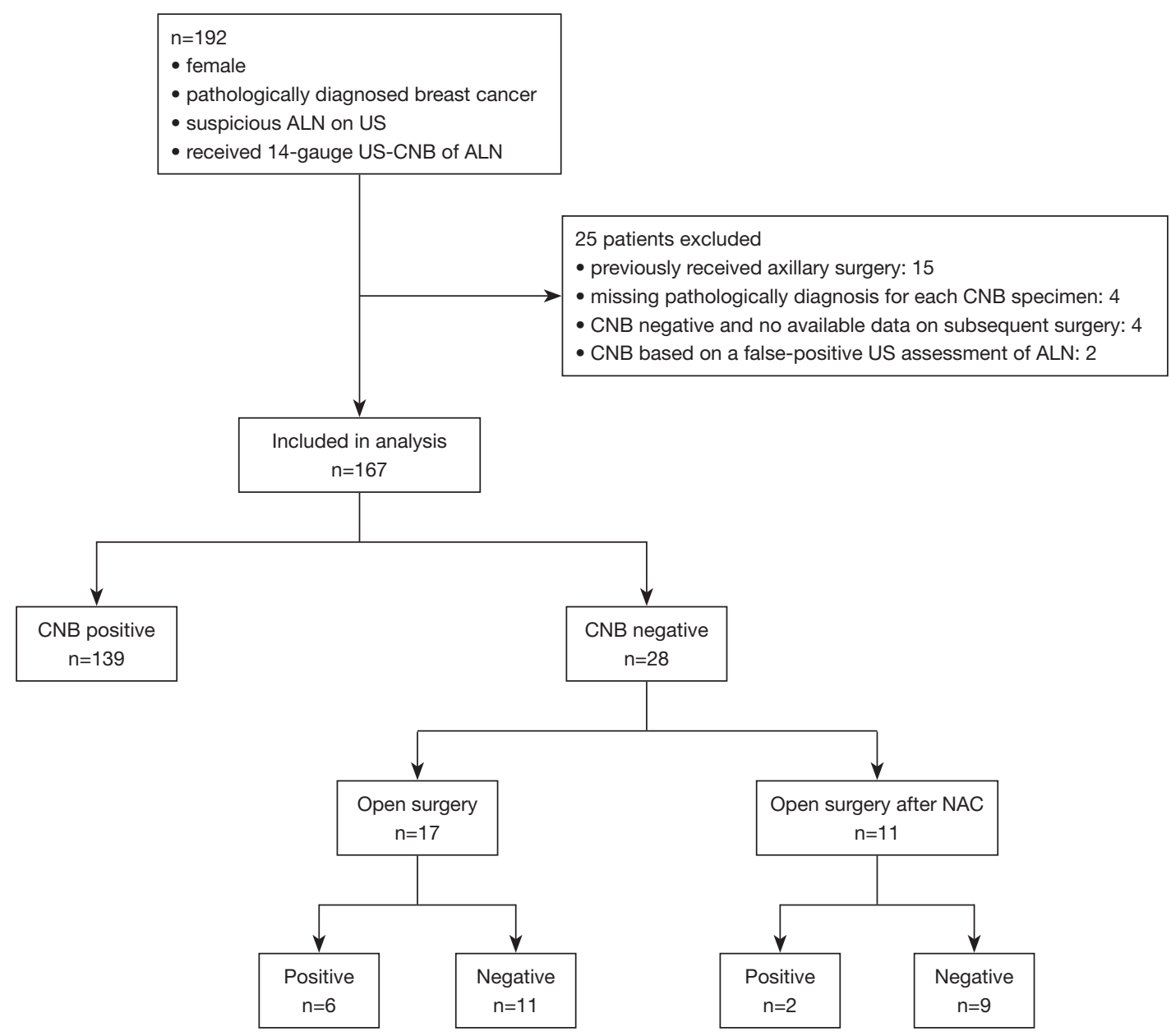

Figure 2 Flowchart of patients. ALN, axillary lymph node; US, ultrasound; CNB, core needle biopsy; NAC, neoadjuvant chemotherapy.

\section{Predictors of requirement for two more CNB specimens}

Among the 147 cases finally diagnosed as ALN-positive, shorter long- and short-axis lengths of the targeted lymph node on US were associated with a false-negative diagnosis based on the first two specimens (both $\mathrm{P}<0.001$ ). Figure 3 shows a representative case. Other characteristics on US (tumor size, number of suspicious ALNs, shape and margin of the ALN, cortex, hilar status, and blood flow of the ALN), the patient's age, tumor characteristics obtained by preoperative biopsy (pathology type, grade, hormone receptor, Ki67, and HER2 status), and N stage after surgery had no significant effect (all $\mathrm{P}>0.05$ ) (Table 3). Due to the relatively small number of false-negative results based on the first two specimens (18 cases), further multivariable analysis was not performed.

\section{Discussion}

This study found that the second specimen contributed significant diagnostic yield of suspicious axillary lymph nodes in core biopsy in breast cancer and additional cores may improve diagnostic yield particularly in patients with small nodes.

US-guided biopsy plays a pivotal role in the preoperative identification of breast cancer and ALN involvement (5). Approximately $50 \%$ of breast cancer patients with ALN metastasis can be identified preoperatively by US combined with US-guided biopsy if ALN was assessed as abnormal (24). US-guided CNB has a lower false-negative rate (FNR) than FNA and has been proved to be safe $(8,9)$; consequently, CNB has replaced FNA as the clinically preferred diagnostic method (18), and the most suspicious 
Table 1 Patient characteristics for the total cohort

\begin{tabular}{|c|c|}
\hline Variable* & No. (\%) \\
\hline Age, median [IQR], years & $51[43-57]$ \\
\hline \multicolumn{2}{|l|}{ US tumor size } \\
\hline $\mathrm{T} 1$ & $21(12.8)$ \\
\hline $\mathrm{T} 2$ & $90(54.9)$ \\
\hline T3 & 53 (32.3) \\
\hline \multicolumn{2}{|l|}{ US no. of suspicious LN } \\
\hline$\leq 3$ & $101(62)$ \\
\hline$\geq 4$ & $62(38)$ \\
\hline \multicolumn{2}{|l|}{ US long-axis of LN, cm } \\
\hline$\leq 1$ & $24(14.5)$ \\
\hline $1-2$ & $79(47.9)$ \\
\hline$>2$ & $62(37.6)$ \\
\hline \multicolumn{2}{|l|}{ US short-axis of LN, cm } \\
\hline$\leq 1$ & 88 (53.3) \\
\hline$>1$ & $77(46.7)$ \\
\hline \multicolumn{2}{|l|}{ US shape of LN } \\
\hline Regular & $152(92.1)$ \\
\hline Irregular & $13(7.9)$ \\
\hline \multicolumn{2}{|l|}{ US margin of LN } \\
\hline Not circumscribed & $6(3.6)$ \\
\hline Circumscribed & $159(96.4)$ \\
\hline \multicolumn{2}{|l|}{ US cortex of LN } \\
\hline No thickening & $5(3.0)$ \\
\hline Thickening & $160(97.0)$ \\
\hline \multicolumn{2}{|l|}{ US hilum of LN } \\
\hline Normal & $18(10.9)$ \\
\hline Compressed or displaced & $147(89.1)$ \\
\hline \multicolumn{2}{|l|}{ US blood flow of LN } \\
\hline Without NHBF & 113(68.5) \\
\hline NHBF & $52(31.5)$ \\
\hline \multicolumn{2}{|l|}{ Tumor pathology $y^{\ddagger}$} \\
\hline Invasive ductal cancer & $135(80.8)$ \\
\hline Other & $32(19.2)$ \\
\hline
\end{tabular}

Table 1 (continued)
Table 1 (continued)

\begin{tabular}{lc}
\hline Variable $^{\star}$ & No. (\%) \\
\hline Tumor grade $^{\ddagger}$ & $1(0.9)$ \\
II & $39(36.1)$ \\
III & $68(63.0)$ \\
Hormone receptor status & \\
Positive & \\
Negative & $104(73.2)$ \\
Ki67 status & $38(26.8)$ \\
High & \\
Low & $107(74.8)$ \\
HER2 status & \\
Positive & $36(25.2)$ \\
Negative & \\
N stage & \\
N0 & $51(39.8)$ \\
N1 & $77(60.2)$ \\
N2 & \\
\hline Na & $34(22.4)$ \\
\hline
\end{tabular}

Values in parentheses are percentages unless indicated otherwise. *, some data are missing; ${ }^{\ddagger}$, data were obtained from surgery specimens; ', cut-off point 14\%. IQR, interquartile range; US, ultrasound; LN, lymph node; NHBF, nonhilar blood flow; HER2, human epidermal growth factor receptor 2 .

node was usually selected for CNB considering the cost of biopsy instruments and the risk of complications. To the best of our knowledge, however, a consensus regarding the ideal number of specimens that should be obtained by US-guided CNB for abnormal ALNs in breast cancer patients has yet to be reached. Obtaining a sufficient but not excessive number of specimens carries the advantages of shortening the procedure time, minimizing complications, and ensuring a good diagnostic performance.

Previous studies have reported numbers of core specimens taken during $\mathrm{CNB}$ ranging from one to six, depending on the preference of the individual radiologist $(8,10,12)$. Although Macaskill et al. (12) analyzed the diagnostic accuracy based on the number of specimens, 
Table 2 Diagnostic performance of different numbers of specimens for evaluating axillary lymph node metastasis

\begin{tabular}{lcccc}
\hline Measure & Specimen 1 (\%) & Specimen 1-2 (\%) & Specimen 1-3 (\%) & Specimen 1-4 (\%) \\
\hline Sensitivity & $74.2(109 / 147)(66.3-81.0)$ & $87.8(129 / 147)(81.3-92.6)$ & $91.2(134 / 147)(85.4-95.2)$ & $94.6(139 / 147)(89.6-97.6)$ \\
Specificity & $100 \%(20 / 20)(83.2-100)$ & $100 \%(20 / 20)(83.2-100)$ & $100 \%(20 / 20)(83.2-100)$ & $100 \%(20 / 20)(83.2-100)$ \\
$\begin{array}{l}\text { Negative } \\
\text { predictive value }\end{array}$ & $34.5(20 / 58)(22.5-48.1)$ & $52.6(20 / 38)(35.8-69.0)$ & $60.6(20 / 33)(42.1-77.1)$ & $71.4(20 / 28)(51.3-86.8)$ \\
$\begin{array}{l}\text { Positive } \\
\text { predictive value }\end{array}$ & $100 \%(109 / 109)(96.7-100)$ & $100 \%(129 / 129)(96.7-100)$ & $100 \%(134 / 134)(96.7-100)$ & $100 \%(139 / 139)(96.7-100)$ \\
Accuracy & $77.3(129 / 167)(70.9-83.7)$ & $89.2(149 / 167)(84.5-93.4)$ & $92.2(154 / 167)(88.1-96.3)$ & $95.2(159 / 167)(92.0-98.4)$ \\
\hline
\end{tabular}

Data in parentheses are numbers used to calculate percentages, and data in brackets are $95 \%$ confidence intervals.


Figure 3 Invasive ductal carcinoma in a 73-year-old woman with a negative result of axillary lymph node CNB but two lymph nodes metastases after surgery. (A) Gray-scale US image of the ipsilateral axilla shows a small $(0.7 \times 0.5 \mathrm{~cm})$ suspicious lymph node with an absent fatty hilum. (B) US image obtained post-firing of CNB shows that the needle passes the lymph node precisely, but the visualization of needle may be caused by the artifact from partial volume effects. CNB, core needle biopsy; US, ultrasound.

their study was based on a very small sample size. In the present study, $74.2 \%(109 / 147)$ and $87.8 \%(129 / 147)$ of ALN metastases were diagnosed in the first and first two specimens, respectively, compared with $81.8 \%$ (45/55) and $96.4 \%$ (53/55), respectively, reported by Macaskill et al. (12). Moreover, the diagnostic yield of the first three specimens in their study was $100 \%(55 / 55)$, compared with 91.2\% (134/147) in our study. Furthermore, Macaskill et al.'s study included only $55 \mathrm{CNB}$-positive cases with three cores per node, and the other 55 cases were CNBnegative. The apparent differences between our results and those of Macaskill et al.'s study may be due to the lower US sensitivity, the smaller sample number of their study, and the different calculation methods used. Five cases were diagnosed with metastasis based on the fourth specimen in our study, with an overall sensitivity for all four specimens of $94.6 \%(139 / 147)$, which was slightly higher than the sensitivity reported in a previous meta-analysis (88\%) (9), but similar to that in a study by Abe et al. (94\%, 64/68) (10).

In this study, the increase $(13.6 \%)$ in diagnostic sensitivity from specimen 1 to specimen 1-2 was significant, which was similar to the increase reported by Macaskill et al. (12). Meanwhile, no significant differences were detected between the sensitivity of specimen $1-3$ versus specimen 1-2, or between specimen 1-4 versus specimen $1-3$, probably due to insufficient statistical power to detect the differences. Therefore, these nonsignificant findings should be interpreted with caution, further studies with larger sample size are needed to confirm these findings.

Among the preoperative US features and tumor characteristics, shorter long- and short-axis lengths of the suspicious lymph node were associated with the lower diagnostic yields of the first two specimens. This may be related to the difficulty in targeting smaller lesions, which 
Table 3 Preoperative patient characteristics and $\mathrm{N}$ stage after surgery in the specimens $1-2$ true-positive and false-negative groups

\begin{tabular}{lccc}
\hline \multirow{2}{*}{ Variable $^{*}$} & \multicolumn{2}{c}{ Specimens 1-2 } & \\
\cline { 2 - 3 } & $\begin{array}{c}\text { True-positive } \\
(\mathrm{n}=129), \text { No. }(\%)\end{array}$ & $\begin{array}{c}\text { False-negative } \\
(\mathrm{n}=18), \text { No. }(\%)\end{array}$ & \\
\hline Age (years) & $50.3 \pm 10.3$ & $51.7 \pm 11.2$ & 0.59 \\
US tumor size & & & 0.93 \\
T1 & $18(14.2)$ & $2(11.1)$ & \\
T2 & $70(55.1)$ & $10(55.6)$ & \\
T3 & $39(30.7)$ & $6(33.3)$ &
\end{tabular}

US no. of suspicious LN

$$
\begin{array}{lll}
\leq 3 & 72(56.7) & 11(64.7) \\
\geq 4 & 55(43.3) & 6(35.3)
\end{array}
$$

US long-axis of LN, cm

$\begin{array}{lll}\leq 1 & 11(8.7) & 7(38.9) \\ 1-2 & 58(45.7) & 9(50.0) \\ >2 & 58(45.7) & 2(11.1)\end{array}$

US short-axis of $\mathrm{LN}, \mathrm{cm}$

$\begin{array}{ccc}\leq 1 & 51(40.2) & 17(94.4) \\ >1 & 76(59.8) & 1(5.6)\end{array}$

US shape of LN

$\begin{array}{lcc}\text { Regular } & 114(86.4) & 18(100) \\ \text { Irregular } & 13(13.6) & 0(0)\end{array}$

US margin of LN

Circumscribed

121 (95.3)

Not

$6(4.7)$

circumscribed

US cortex of LN

No thickening

$3(2.4)$

Thickening

124 (97.6)

US hilar of LN

$\begin{array}{lcc}\text { Normal } & 8(6.3) & 2(11.1) \\ \begin{array}{l}\text { Compressed } \\ \text { or displaced }\end{array} & 119(93.7) & 16(88.9)\end{array}$

US blood flow of LN
18 (100)

$0(0)$

0.93

0.53

$<0.001$

$<0.001$

$$
0.37
$$

1.00

0.42

0.36
86 (67.7)

12 (66.7)

NHBF

$41(32.3)$

\begin{tabular}{|c|c|c|c|}
\hline \multirow[b]{2}{*}{ Variable* } & \multicolumn{2}{|c|}{ Specimens 1-2 } & \multirow[b]{2}{*}{$P$ value } \\
\hline & $\begin{array}{c}\text { True-positive } \\
(n=129), \text { No. }(\%)\end{array}$ & $\begin{array}{l}\text { False-negative } \\
(n=18), \text { No. }(\%)\end{array}$ & \\
\hline \multicolumn{3}{|c|}{ CNB tumor pathology } & 0.60 \\
\hline $\begin{array}{l}\text { Invasive ductal } \\
\text { cancer }\end{array}$ & $104(80.6)$ & $16(88.9)$ & \\
\hline Others & $25(19.4)$ & $2(11.1)$ & \\
\hline \multicolumn{3}{|l|}{ CNB tumor grade } & 1.00 \\
\hline II & $54(67.5)$ & $6(66.7)$ & \\
\hline III & $26(32.5)$ & $3(33.3)$ & \\
\hline \multicolumn{3}{|c|}{ CNB hormone receptor status } & 0.17 \\
\hline Positive & $73(73.0)$ & 14 (93.3) & \\
\hline Negative & $27(27.0)$ & $1(6.7)$ & \\
\hline \multicolumn{3}{|l|}{ CNB Ki67 status $^{\ddagger}$} & 0.07 \\
\hline High & $97(98.0)$ & $12(85.7)$ & \\
\hline Low & $2(2.0)$ & $2(14.3)$ & \\
\hline \multicolumn{3}{|l|}{ CNB HER2 status } & 1.00 \\
\hline Positive & 39 (41.9) & $3(37.5)$ & \\
\hline Negative & $54(58.1)$ & $5(62.5)$ & \\
\hline \multicolumn{3}{|l|}{$\mathrm{N}$ stage } & 0.17 \\
\hline No & $24(21.1)$ & $0(0)$ & \\
\hline $\mathrm{N} 1$ & $41(36.0)$ & 7 (38.9) & \\
\hline N2 & $28(24.6)$ & $6(33.3)$ & \\
\hline N3 & $21(18.4)$ & $5(27.8)$ & \\
\hline
\end{tabular}

6 (33.3)
Table 3 (continued)

Values in parentheses are percentages unless indicated otherwise. *, some data are missing; ${ }^{\ddagger}$, cut-off point 14\%. IQR, interquartile range; US, ultrasound; LN, lymph node; NHBF, non-hilar blood flow; CNB, core needle biopsy; HER2, human epidermal growth factor receptor 2 .

introduces a greater possibility of sampling error $(25,26)$. Although longitudinal (along the needle) imaging postfiring was used to ensure that the needle passed the lesion, determining this may be subjective and could be affected by partial-volume effects towards the periphery of the lymph node, which has a greater influence in small lesions (26). Visualization by another image in the orthogonal plane before the removal of the needle, as well as validation by three-dimensional US, may help to evaluate the post-firing

Table 3 (continued) 
needle placement more precisely (26-28). Therefore, in cases with small ALNs at CNB, more specimens are needed to make an accurate diagnosis.

$\mathrm{CNB}$ with four specimens failed to achieve a diagnosis in 8 cases (FNR $5.4 \%, 8 / 147$ ) that were subsequently confirmed as metastasis after surgery. These false-negative results may be attributable to two main reasons. First, CNB did not precisely target the metastatic deposits in the suspicious ALN, in which case increasing the number of specimens might elevate the possibility of a positive diagnosis by CNB. Second, the ALN targeted by CNB was not the SLN and was non-metastatic; therefore, obtaining more specimens would not reduce the FNR. Previous studies found that only $64-78 \%$ of lymph nodes that underwent CNB corresponded with the SLNs removed at surgery $(29,30)$. Precise targeting of the SLN guided by a gamma-probe, contrast-enhanced US, or elastography imaging is a promising method for reducing the CNB FNR (31-33). The negative predictive value of $\mathrm{CNB}$ with four specimens in the study was $71.4 \%$ (20/28), which suggests that further management of CNB-negative axilla should not be abandoned. Similar to our results, a recent meta-analysis reported that one in four women with a US-guided biopsy"proven" negative axilla had a positive result after SLN biopsy (24). However, US combined with needle biopsy could serve as a potential alternative to SLN biopsy for axillary staging in selected patients $(34,35)$.

This study had several limitations. First, this is an exploratory study and we didn't define the statistical power and calculate the required sample size due to limited published data, therefore, cautions should be made in interpreting the non-significant findings of specimen 3/4. Second, we did not compare the CNB-sampled and surgically removed ALNs, which creates uncertainty as to how many of the eight lymph nodes from patients with CNB FNRs ultimately had metastasis. Third, 11 of 28 patients with CNB-negative results underwent surgery after NAC, 9 of whom had no evidence of lymph node metastasis; however, some of these patients may have benefitted from NAC and were subsequently mistaken as true-negative cases.

\section{Conclusions}

In conclusion, although the second specimen contributed significant diagnostic yield of suspicious axillary lymph nodes in core biopsy in breast cancer, the current findings do not provide data to indicate how many more than two specimens are sufficient. Additional specimens may improve diagnostic yield particularly in patients with small nodes. Further studies with pre-defined statistical power requirement are needed to confirm this observation.

\section{Acknowledgments}

Funding: This work is supported by the National Key R\&D Program of China (2017YFC1309103 and 2017YFC1309104); the Natural Science Foundation of China (81672594, 81772836, 81872139 and 82072907); Clinical Innovation Project of Bioland Laboratory (Guangzhou Regenerative Medicine and Health Guangdong Laboratory, 2018GZR0201004); Sun Yatsen Memorial Hospital Cultivation Project for Clinical Research (SYS-C-201805); Key Projects of the National Natural Science Foundation of China (51861125203); Project of Beijing Xisike Clinical Oncology Research Foundation (Y-Roche2019/2-0078); Guangzhou Science and Technology Key Projects (201804020076).

\section{Footnote}

Conflicts of Interest: All authors have completed the ICMJE uniform disclosure form (available at http://dx.doi. org/10.21037/qims-20-1030). The authors have no conflicts of interest to declare.

Ethical Statement: The study was conducted in accordance with the Declaration of Helsinki (as revised in 2013). This study was approved by the ethics committee of Sun Yatsen Memorial Hospital (No. 2018-44). Written informed consent was obtained from all study participants.

Open Access Statement: This is an Open Access article distributed in accordance with the Creative Commons Attribution-NonCommercial-NoDerivs 4.0 International License (CC BY-NC-ND 4.0), which permits the noncommercial replication and distribution of the article with the strict proviso that no changes or edits are made and the original work is properly cited (including links to both the formal publication through the relevant DOI and the license). See: https://creativecommons.org/licenses/by-nc-nd/4.0/.

\section{References}

1. Humphrey KL, Saksena MA, Freer PE, Smith BL, Rafferty EA. To do or not to do: axillary nodal 
evaluation after ACOSOGZ0011 Trial. Radiographics 2014;34:1807-16.

2. Boughey JC, Moriarty JP, Degnim AC, Gregg MS, Egginton JS, Long KH. Cost modeling of preoperative axillary ultrasound and fine-needle aspiration to guide surgery for invasive breast cancer. Ann Surg Oncol 2010;17:953-8.

3. Veronesi U, Paganelli G, Viale G, Luini A, Zurrida S, Galimberti V, Intra M, Veronesi P, Robertson C, Maisonneuve P, Renne G, De Cicco C, De Lucia F, Gennari R. A randomized comparison of sentinel-node biopsy with routine axillary dissection in breast cancer. $\mathrm{N}$ Engl J Med 2003;349:546-53.

4. Lyman GH, Giuliano AE, Somerfield MR, Benson III AB, Bodurka DC, Burstein HJ, Cochran AJ, Cody III HS, Edge SB, Galper S. American Society of Clinical Oncology guideline recommendations for sentinel lymph node biopsy in early-stage breast cancer. J Clin Oncol 2005;23:7703-20.

5. National comprehensive cancer network. NCCN guidelines. Available online: https://www.nccn.org/ professionals/physician_gls/default.aspx

6. Department of Health. Diagnosis, staging and treatment of patients with breast cancer. National Clinical Guideline No. 7. June 2015. ISSN 2009-6259. Available online: https://www.hse.ie/eng/services/list/5/cancer/profinfo/ guidelines/breast/breastguideline.pdf

7. Marino MA, Avendano D, Zapata P, Riedl CC, Pinker K.Lymph Node Imaging in Patients with Primary Breast Cancer: Concurrent Diagnostic Tools. Oncologist 2020;25:e231-42.

8. Rautiainen S, Masarwah A, Sudah M, Sutela A, Pelkonen O, Joukainen S, Sironen R, Karja V, Vanninen R. Axillary lymph node biopsy in newly diagnosed invasive breast cancer: comparative accuracy of fine-needle aspiration biopsy versus core-needle biopsy. Radiology 2013;269:54-60.

9. Balasubramanian I, Fleming CA, Corrigan MA, Redmond HP, Kerin MJ, Lowery AJ. Meta-analysis of the diagnostic accuracy of ultrasound-guided fine-needle aspiration and core needle biopsy in diagnosing axillary lymph node metastasis. Br J Surg 2018;105:1244-53.

10. Abe H, Schmidt RA, Kulkarni K, Sennett CA, Mueller JS, Newstead GM. Axillary lymph nodes suspicious for breast cancer metastasis: sampling with US-guided 14-gauge core-needle biopsy--clinical experience in 100 patients. Radiology 2009;250:41-9.

11. Houssami N, Ciatto S, Turner RM, Cody HS 3rd, Macaskill P. Preoperative ultrasound-guided needle biopsy of axillary nodes in invasive breast cancer: meta-analysis of its accuracy and utility in staging the axilla. Ann Surg 2011;254:243-51.

12. Macaskill EJ, Purdie CA, Jordan LB, McLean D, Whelehan P, Brown DC, Evans A. Axillary lymph node core biopsy for breast cancer metastases -- how many needle passes are enough? Clin Radiol 2012;67:417-9.

13. Hu Y, Yang Y, Gu R, Jin L, Shen S, Liu F, Wang H, Mei J, Jiang X, Liu Q. Does patient age affect the PPV 3 of ACR BI-RADS Ultrasound categories 4 and 5 in the diagnostic setting? Eur Radiol2018;28:2492-8.

14. Mendelson E, Böhm-Vélez M, Berg W, Whitman G, Feldman M, Madjar H. ACR BI-RADS ultrasound. ACR BI-RADS Atlas, Breast Imaging Reporting and Data System 5th ed Reston, VA: American College of Radiology, 2013:1-173.

15. Koelliker SL, Chung MA, Mainiero MB, Steinhoff MM, Cady B. Axillary lymph nodes: US-guided fine-needle aspiration for initial staging of breast cancer--correlation with primary tumor size. Radiology 2008;246:81-9.

16. Neal CH, Daly CP, Nees AV, Helvie MA. Can preoperative axillary US help exclude N2 and N3 metastatic breast cancer? Radiology 2010;257:335-41.

17. Abe H, Schmidt RA, Sennett CA, Shimauchi A, Newstead GM. US-guided core needle biopsy of axillary lymph nodes in patients with breast cancer: why and how to do it. Radiographics 2007;27 Suppl 1:S91-9.

18. Ecanow JS, Abe H, Newstead GM, Ecanow DB, Jeske $\mathrm{JM}$. Axillary staging of breast cancer: what the radiologist should know. Radiographics 2013;33:1589-612.

19. Maxwell F, de Margerie Mellon C, Bricout M, Cauderlier E, Chapelier M, Albiter M, Bourrier P, Espie M, de Kerviler E, de Bazelaire C. Diagnostic strategy for the assessment of axillary lymph node status in breast cancer. Diagn Interv Imaging 2015;96:1089-101.

20. Bedi DG, Krishnamurthy R, Krishnamurthy S, Edeiken BS, Le-Petross H, Fornage BD, Bassett RL Jr, Hunt KK. Cortical morphologic features of axillary lymph nodes as a predictor of metastasis in breast cancer: in vitro sonographic study. AJR Am J Roentgenol2008;191:646-52.

21. Parkinson AV, Cannon CR, Hayne ST. Color coding surgical margins with the Davidson marking system. Journal of Histotechnology1990;13:293-5.

22. Denison CM, Lester SC. Essential Components of a Successful Breast Core Needle Biopsy Program: Imaging Modalities, Sampling Techniques, Specimen Processing, Radiologic/Pathologic Correlation, and Appropriate Follow-Up. In: Shin S. editor. A Comprehensive Guide 
to Core Needle Biopsies of the Breast. Springer, Cham, 2016:3-47.

23. Mullen R, Purdie CA, Jordan LB, McLean D, Whelehan P, Vinnicombe S, Brown DC, Evans A. Can additional histopathological examination of ultrasound-guided axillary lymph node core biopsies improve preoperative diagnosis of primary breast cancer nodal metastasis? Clin Radiol 2013;68:704-7.

24. Diepstraten SCE, Sever AR, Buckens CFM, Veldhuis WB, Verkooijen HM. Value of preoperative ultrasoundguided axillary lymph node biopsy for preventing completion axillary lymph node dissection in breast cancer: a systematic review and meta-analysis. Ann Surg Oncol2014;21:51-9.

25. Wu JS, Goldsmith JD, Horwich PJ, Shetty SK, Hochman MG. Bone and soft-tissue lesions: what factors affect diagnostic yield of image-guided core-needle biopsy? Radiology 2008;248:962-70.

26. Fishman JE, Milikowski C, Ramsinghani R, Velasquez MV, Aviram G. US-guided core-needle biopsy of the breast: how many specimens are necessary? Radiology 2003;226:779-82.

27. Harvey JA, Moran RE, DeAngelis GA. Technique and pitfalls of ultrasound-guided core-needle biopsy of the breast. Semin Ultrasound CT MR 2000;21:362-74.

28. Sauer G, Deissler H, Strunz K, Helms G, Remmel E, Koretz K, Terinde R, Kreienberg R. Ultrasound-guided large-core needle biopsies of breast lesions: analysis of 962 cases to determine the number of samples for reliable tumour classification. Br J Cancer 2005;92:231-5.

29. Britton PD, Provenzano E, Barter S, Gaskarth M, Goud A, Moyle P, Sinnatamby R, Wallis M, Benson J, Forouhi P. Ultrasound guided percutaneous axillary lymph node

Cite this article as: $\mathrm{Hu} \mathrm{Y}$, Mei J, Yang Y, Gu R, Zhong J, Jiang X, Liu F, Yong J, Wang H, Shen S, Liang J, Liu Q, Gong C. Specimen number based diagnostic yields of suspicious axillary lymph nodes in core biopsy in breast cancer: clinical implications from a prospective exploratory study. Quant Imaging Med Surg 2021;11(5):2151-2161. doi: 10.21037/qims20-1030 core biopsy: how often is the sentinel lymph node being biopsied? Breast 2009;18:13-6.

30. Nathanson SD, Burke M, Slater R, Kapke A. Preoperative identification of the sentinel lymph node in breast cancer. Ann Surg Oncol 2007;14:3102-10.

31. Whelehan P, Vinnicombe S, Brown D, McLean D, Evans A. Accuracy of non-operative identification of the sentinel lymph node using combined gamma and ultrasound scanning. Clin Radiol2014;69:849-52.

32. Sever AR, Mills P, Weeks J, Jones SE, Fish D, Jones PA, Mali W. Preoperative needle biopsy of sentinel lymph nodes using intradermal microbubbles and contrastenhanced ultrasound in patients with breast cancer. AJR Am J Roentgenol 2012;199:465-70.

33. Taylor K, O'Keeffe S, Britton P, Wallis M, Treece G, Housden J, Parashar D, Bond S, Sinnatamby R. Ultrasound elastography as an adjuvant to conventional ultrasound in the preoperative assessment of axillary lymph nodes in suspected breast cancer: a pilot study. Clin Radiol 2011;66:1064-71.

34. Gentilini O, Veronesi U. Abandoning sentinel lymph node biopsy in early breast cancer? A new trial in progress at the European Institute of Oncology of Milan (SOUND: Sentinel node vs Observation after axillary UltraSouND). Breast 2012;21:678-81.

35. Washington University School of Medicine. Axillary ultrasound with or without sentinel lymph node biopsy in detecting the spread of breast cancer in patients receiving breast conservation therapy [ClinicalTrials.gov identifier NCT01821768]. US National Institutes of Health, ClinicalTrials.gov. Available online: https://clinicaltrials. gov/ct2/show/NCT01821768 